\title{
El espacio urbano de La Habana como discurso: entre la historia y la memoria
}

\author{
Ana CASAdo FERnÁNDEZ \\ Departamento de Filología Española IV \\ Universidad Complutense de Madrid \\ anacasadofernandez@gmail.com
}

Recibido: 17 de marzo de 2011

Aceptado: 5 de mayo de 2011

\section{Resumen}

En este artículo se analizará el espacio urbano de la ciudad de La Habana a través de la literatura. El estudio está vinculado a tres breves periodos históricos del siglo XX en los que la ciudad sufrió diversas transformaciones: los años treinta, durante los cuales diversos escritores e intelectuales españoles residieron temporalmente en La Habana; los años cincuenta, que representan una época de gran esplendor $y$, finalmente, los años posteriores al triunfo de la revolución como periodo de cambio social y exilio.

Palabras clave: espacio urbano, La Habana, discurso, historia, memoria.

Title: The urban space of Havana as discourse: between history and memory

\section{Abstract}

The article analyses the literary representation of Havana's urban space. It focuses on three brief historical periods of the 20th century, during which the city suffered important changes: the thirties, when several Spanish intellectuals resided temporarily in Havana; the ebullient decade of the fifties and, finally, the years of social transformation and exile after the victory of the revolution.

Keywords: urban space, Havana, discourse, history, memory.

\section{Índice}

1. Introducción

2. Los años treinta o las ciudades homónimas

3. Los años cuarenta y cincuenta: La Habana, de ciudad morfológica a ciudad semántica

4. Los años posteriores al triunfo de la Revolución: La Habana, ciudad de la memoria y ciudad en ruinas 


\section{Introducción}

Este estudio toma como punto de partida los postulados que Roland Barthes desarrolló en su artículo "Semiología y urbanismo" en el cual afirma que la ciudad es un discurso cuyos significantes y significados deben ser legibles e identificables por quien la habita (Barthes 2009: 349). El lector $y$, en este caso, los escritores que recorren la topografía urbana de la Habana, son descodificadores de ese espacio urbano en tanto que lo identifican con su lugar de origen (los escritores españoles que habitaron en La Habana durante los años treinta), la exteriorizan / interiorizan (Alejo Carpentier y José Lezama Lima) o la convierten en espacio de memoria (Guillermo Cabrera Infante).

\section{Los años treinta o las ciudades homónimas}

En los años treinta algunos escritores e intelectuales españoles se instalaron en Cuba, y específicamente en la ciudad de La Habana, ya fuera por motivos políticos (huyeron al exilio tras el estallido de la Guerra Civil), como fue el caso de María Zambrano o Juan Ramón Jiménez, ya fuera por motivos personales (el viaje), como fue el caso de Federico García Lorca. Muchos de estos escritores percibieron La Habana como un reflejo de su ciudad de origen y establecieron en ella vínculos morfológicos con la ciudad abandonada (Málaga, Huelva, Granada), si bien semánticamente no se corresponderían la ciudad de origen con la ciudad que les acoge, ciudades, a un tiempo, homónimas y disémicas.

María Zambrano consideró La Habana su "patria pre-natal", lugar en el que fue capaz de enraizarse una vez desterrada de su patria. Cuba, y la Habana en concreto, son la "substancia" que alimenta su espíritu, la compensación por el dolor que le provoca el exilio, ya que en ese nuevo espacio habitado, La Habana, cree ver a su Málaga originaria. Así se dirige a Lezama Lima en una carta escrita desde Roma:

Veo que dejé raíces en La Habana donde yo me quedé por sentirlas muy en lo hondo de mí misma. En aquel domingo de mi llegada en que le conocí la sentí recordándomela, creía volver a Málaga con mi padre joven vestido de blanco - de alpaca- y yo de niña en un coche de caballos. Algo en el aire, en las sombras de los árboles, en el rumor del mar, en la brisa, en la sonrisa y en un misterio familiar. $Y$ siempre pensé que al haber sido arrancada tan pronto de Andalucía tenía que darme el destino esa compensación de vivir en La Habana tanto tiempo, pues que las horas de la infancia son más lentas. Y ha sido así. (Zambrano 1996: 207)

Juan Ramón Jiménez también identifica la ciudad de La Habana con diversas ciudades de su Andalucía. La ciudad de La Habana es un 
espacio pre-conocido / pre-contemplado por el poeta, preinscrito en él con la misma "substancia" de la que hablaba María Zambrano y reinscrito de nuevo en él al hallarse en el presente frente a ella.

Mucha Habana había en Moguer, en Huelva, en Cádiz, en Sevilla. iCuántas veces, en todas mis vidas, con motivos gratos 0 lamentables, pacíficos o absurdos, he pensado profundamente en La Habana, en Cuba! La extensa realidad ha superado el total de mis sueños y mis pensamientos; aunque, como otras veces al "conocer" una ciudad, la ciudad presente me haya vuelto al revés su imagen de ausencia y se hayan quedado las dos luchando en mi cámara oscura. Mi nueva visión de La Habana, de la Cuba que he tocado, su existencia vista, quedan ya incorporadas a lo mejor del tesoro de mi memoria. (Jiménez apud Estévez 2004: 150)

Por su lado, Federico García Lorca estuvo durante tres meses en La Habana, en 1930, después de su estancia en Nueva York y, al igual que María Zambrano y Juan Ramón, identifica el espacio de La Habana con el de su origen, una analogía morfológica para el extranjero que habita un nuevo espacio y pone en marcha un mecanismo de relaciones espaciales que aminoran la extrañeza y el desarraigo.

¿Pero qué es esto? ¿Otra vez España? ¿Otra vez la Andalucía mundial? Es el amarillo de Cádiz con un grado más, es el rosa de Sevilla tirando a carmín y el verde de Granada con una leve fosforescencia de pez. (García Lorca apud Estévez 2004: 144)

Además de esta consolidación de ciudades homónimas entre La Habana y las ciudades de origen de los escritores españoles en Cuba, otro vínculo común entre ellos es la identificación del nuevo lugar que es La Habana (ámbito espacial) con un tiempo vital específico, la infancia, por lo que espacio y tiempo se amalgaman en una misma unidad cronotópica. María Zambrano concibe la llegada a este nuevo espacio urbano como un retorno a su infancia y asimila su situación de destierro como adulta en Cuba, que implica movimiento físico, con el destierro como niña, que es más un destierro estático, interior.

En La Habana recobré mis sentidos de niña, y la cercanía del misterio, y esos sentires que eran al par del destierro y de la infancia, pues todo niño se siente desterrado. Por eso quise sentir mi destierro allí donde se me ha confundido con mi infancia. (Zambrano 1996: 208)

Juan Ramón explica su pre-conocimiento de La Habana desde la infancia antes de llegar físicamente hasta ella: "La Habana está en mi imajinación y mi anhelo andaluces, desde niño" (Jiménez apud Estévez 2004: 150). 
En Lorca, la vinculación del espacio de La Habana con el ámbito temporal de la infancia se muestra materializada en el olor de los habanos y las iconografías de las cajas de tabaco que llegaban hasta Fuentevaqueros, así como en la música típicamente cubana, las habaneras. Desde La Habana escribe a sus padres una carta en la que dice:

Estuve en casa del músico Sánchez de Fuentes, que es autor de la habanera "Tú", que me cantabais de niño, "La palma que en el bosque se mece gentil", y dedicó un ejemplar para mamá. (García Lorca apud Hernández 2009: 76)

La Habana para el viajero o exiliado es la ciudad que acontece en el presente al mismo tiempo que es la ciudad que aconteció en el pasado, a pesar de que presente y pasado signifiquen de distinta manera.

\section{Los años cuarenta y cincuenta: La Habana, de ciudad morfológica a ciudad semántica}

El paso del topos, el lugar que se concreta por el construir y el habitar, al logos, la descripción de ese lugar (Aínsa 2002: 15), se consolida en la ciudad de La Habana durante los años cuarenta y cincuenta, a través de dos figuras fundamentales: Alejo Carpentier y José Lezama Lima.

Carpentier, que estudió arquitectura y fue un gran amante de la capital cubana, escribe una serie de crónicas habaneras (entre las que se incluye el ensayo La ciudad de las columnas) en la que se manifiesta su gusto por la exterioridad urbana, aplicando minuciosos detalles sobre cada uno de los elementos que conforman la ciudad morfológicamente.

Con la columna, la reja, el guardavecinos, el guardacantón -a veces un motivo de adorno, en el remate de una ventana; un encaje de madera calada; un mascarón; una boca de gárgola en la esquina de un tejado-, el estilo cubano se ha definido para la calle. (Carpentier 2004: 107)

Ciudad ecléctica, amalgamada por diferentes estilos arquitectónicos en convivencia que, sin un estilo definido, se distingue precisamente por la ausencia de este. A pesar de ello, una de las constantes que la ciudad repite en su discurso (visual y textual) es la columna.

Una ciudad que es emporio de columnas, selva de columnas, columnata infinita, última urbe en tener columnas en tal demasía; columnas que, por lo demás, al haber salido de los patios originales, 
han ido trazando una historia de la decadencia de la columna a través de las edades. (Carpentier 2004: 85)

La columna sostiene la ciudad, la yergue en su belleza, la espacializa y, a la vez, confiere a la ciudad temporalidad física o corporal. Por un lado la columna muestra la amalgama de los distintos estilos adoptados a lo largo de diferentes épocas, y por otro lado, muestra el decaimiento físico al que ha llegado la propia ciudad -junto a las columnas- a causa del paso del tiempo. De nuevo el ámbito espacial se vincula al ámbito temporal en ese cronotropo urbano antes mencionado.

Alejo Carpentier describe en sus crónicas cada uno de los elementos urbanos de La Habana teniendo en cuenta su funcionalidad (los soportales interiores construidos para proteger del sol o de la lluvia, los guardavecinos para separar unos balcones de otros, etc.) desarrollando así una para-arquitectura en el sentido de que todo elemento espacial urbano debe cumplir la finalidad para el que fue construido.

Lezama Lima, sin embargo, traslada cada uno de estos elementos morfológicos urbanos a un plano semántico, es decir, a su significación más personal. Lezama Lima, en definitiva, interioriza la ciudad; al igual que con el alimento -"comer, incorporar mundo exterior a nuestra sustancia" (Lezama Lima 2009: 243)-, Lezama convierte lo exterior de la ciudad en substancia interior, dotando al espacio urbano de una significación simbólica.

María Zambrano describe en su artículo "Lezama Lima en La Habana" la relación que el escritor estableció con su ciudad de origen, una relación basada en el vínculo espacio-temporal a través del cuerpo: habitar verdaderamente un espacio es, al mismo tiempo, habitar su tiempo, conformar el cuerpo a ese espacio constituido de tiempo.

El habitar en un lugar, el llevarlo consigo en ciertas situaciones, va unido a la posibilidad de disponer de ese presente precioso que es la contemplación [...]. Pues cuando alguien habita verdaderamente un lugar, como José Lezama Lima La Habana, cuando el laberinto que forman las propias entrañas reclama ser recorrido y resulta ser coincidente con el laberinto de su ciudad, podría decirse en lenguaje filosófico que el propio, personal laberinto y su reclamo resultan ser trascendental según espacio y tiempo. (Zambrano 1968: 10)

Lezama transforma el espacio urbano de La Habana en un espacio trascendental a través de la asimilación y escritura de las coordenadas espacio-temporales de la ciudad. Lezama nos muestra los espacios urbanos en relación con sus moradores y siempre desde una perspectiva puramente semántica: el paseo ("destinado al desfile, a mostrar") y las calles ("que exhuman sus disfraces de 
personas"), los parques ("como un retiro y es en su soledad donde se elabora el oro apagado del recuerdo"), la guagua ("monstruo que inquieta y aparece tres veces al día"), el café (lugar para anclarse "a donde llegan los paseantes de un escepticismo regalado"), las librerías y feria del libro donde "los libros se unen a los sumergidos desfiles de los recuerdos" (Lezama Lima 2009: 204-223). El ámbito temporal es muchas veces el que transforma la espacialidad de lo urbano, así, por ejemplo, en la última semana del mes los días son "más sutiles en sus cambiantes estados de ánimo [...] los moradores de la ciudad se aíslan, no salen a la calle, suprimen las visitas" (Lezama Lima 2009: 217).

Lezama Lima toma como modelo de ciudad a la polis griega, la ciudad-Estado en la que esta tenía la medida del hombre, en la se edificaba "hasta los consentimientos del ojo, hasta la extensión de la mirada" (Lezama Lima 2009: 240), y la vincula directamente con La Habana. Para Lezama el hombre habita la ciudad y la conforma, al mismo tiempo que la ciudad habita al hombre y lo conforma, es decir, hay una influencia bidireccional entre hombre y ciudad por la que ambos forman un todo: espacio corporal humano y espacio monumental urbano se funden constituyendo al hombre-ciudad o a la ciudad-hombre.

Siente el artista su ciudad, su contorno, la historia de sus casas, sus chismes, las familias en sus uniones de sangre, sus emigraciones, los secretos que se inician [...]. La Habana conserva todavía la medida del hombre. El hombre le recorre los contornos, le encuentra su centro, tienen sus zonas de infinitud y soledad donde le llega lo terrible. (Lezama Lima 2009: 223)

Si para Alejo Carpentier el tiempo y la historia de la ciudad se mostraban a través del aspecto exterior de las columnas, "una historia de la decadencia de las columnas a través de las edades" (Carpentier 2004: 85), Lezama Lima irá más allá de la pura exterioridad urbana para adentrarse en su interior, en lo que denomina "la tristeza de la piedra" (Lezama Lima 2009: 209).

\section{Los años posteriores al triunfo de la Revolución: La Habana, ciudad de la memoria y ciudad en ruinas}

Tras el triunfo de la revolución en 1959 diversos intelectuales cubanos abandonaron Cuba por no participar de las ideas y actuación del régimen castrista. Cuba, y La Habana concretamente, que en los años treinta acogió a distintos intelectuales españoles, ahora era abandonada por aquellos que no conciliaban la situación de su país. Los escritores exiliados mantendrán un diálogo continuo a través de sus escritos con la ciudad de La Habana. Esta se mantiene viva a 
través de la memoria y a través del lenguaje, vehículos de aprehensión de dicho espacio.

El caso de Guillermo Cabrera Infante merece ser destacado. Desde su exilio -"salí de Cuba el 3 de octubre de 1965" afirma (Cabrera Infante 1992: 16)- el escritor cubano nos ofrece en distintas obras (Tres tristes tigres publicada en 1967 y La Habana para un infante difunto publicada en 1979) una reproducción de La Habana en su época de esplendor, los años cuarenta y cincuenta, en la que se plantea que la ciudad posee su propio lenguaje -"la ciudad hablaba otra lengua" (Cabrera Infante 2007: 12)-, no solo por los nuevos vocablos que ella misma despliega, sino porque son los espacios urbanos los que proporcionan ese lenguaje. Por ejemplo, el solar se presenta como una colmena depravada donde se eliminan las fronteras de lo privado y lo público; el cine es el espacio erótico o de alteridad en el encuentro con el otro; la calle es el espacio sensorial que penetra por todos los poros de los que la transitan; los clubs, discotecas y cabarets son los espacios nocturnos del momento. Durante los años cuarenta y cincuenta habaneros que Cabrera Infante reproduce en sus novelas, se habían asimilado en Cuba los postulados del Movimiento Moderno y los modelos arquitectónicos del American Way of Life (Izquierdo 2002: 56). Fueron construidos rascacielos, clubs y centros recreativos como el cabaret Tropicana (espacio de Tres Tristes Tigres), así como supermercados, tiendas y "shopping centers". La transformación de la ciudad en estos años, su ritmo acelerado, vino representada por el automóvil y por el desplazamiento del centro urbano hacia el oeste, en El Vedado y Miramar.

Cabrera Infante vivió los años de esplendor y prosperidad de La Habana como la mejor época de su vida en la isla y por ello no admitió otra Habana que no fuera la de esos años. Rafael Rojas, en su ensayo titulado Tumbas sin sosiego. Revolución, disidencia y exilio del intelectual cubano, describe la relación corporal que Cabrera Infante establece con La Habana durante estos años de auge.

Cabrera Infante sintió la transformación urbana del último tramo de la historia republicana como se siente el crecimiento del propio cuerpo. Nacido en 1929, durante el esplendor cultural de la República, el autor llegó a la adultez justo cuando la ciudad adoptaba la nueva fisonomía de la modernidad americana. (Rojas 2006: 256257)

En Tres tristes tigres y La Habana para un infante difunto el escritor realiza un enorme ejercicio de memoria para mostrarnos su auténtica Habana, "aquella Habana profundamente occidental, abierta a las corrientes estéticas de la posguerra" (Rojas 2006: 260), que había desaparecido entre 1959 y 1961. 
Desde la distancia del exilio, Cabrera Infante reflexionó sobre La Habana revolucionaria, ciudad que ya no reconoce, que le es ajena y extranjera porque su ritmo, su movimiento se ha ido apagando; ciudad, en suma, disfrazada, falsa, momificada.

En vez de una ciudad prodigiosa es un doble a través del espejo, restaurada ruina, ciudad de pesadilla [...]. No puede haber fin más triste, en el laconismo de una ciudad que era locuaz, hablantina, la patria de los hablaneros. Los lacónicos la habitan ahora y La Habana ha devenido una ciudad fantasma para turistas y torpes. Su encanto no es la vida, sino los colorines de un pájaro disecado: loro, papagayo. (Cabrera Infante 1992: 125)

A diferencia de los escritores españoles exiliados en Cuba, Cabrera Infante no realiza una búsqueda homónima de la ciudad de La Habana en las nuevas ciudades habitadas tras el exilio (Madrid, Barcelona, Londres), no es una búsqueda en la que quiera vincularse la forma de la ciudad de La Habana con la nueva ciudad, como ocurría con los exiliados españoles, sino que Cabrera Infante realiza una búsqueda semántica, es decir, que el significado de La Habana en una época concreta, la de los años cuarenta y cincuenta, se corresponda con el significado de la ciudad que le acoge. Es, por lo tanto, la búsqueda de una ciudad sinonímica: "Es así que he buscado en otras ciudades el esplendor que fue La Habana" (Cabrera Infante 1999: 14).

En conclusión, estos tres periodos históricos analizados (años treinta, años cuarenta y cincuenta, años posteriores al triunfo de la revolución) muestran las metamorfosis que la ciudad, como cuerpo y entraña, ha sufrido a lo largo de la historia del siglo XX. La Habana ha ido transformando su forma y su significado progresivamente (ciudad homónima, ciudad morfológica, ciudad semántica, ciudad de la memoria, ciudad en ruinas) en un cambio que parte de una concepción vital de la ciudad y que desemboca en la desaparición de sí misma.

La Habana hoy parece una ciudad derruida, no desde el aire como Berlín sino desde dentro. (Cabrera Infante 1999:14)

Nacimos en un oasis y con un pase de mano nos encontramos en pleno desierto (Cabrera Infante 2010: 553) 


\section{Bibliografía}

AÍNSA, Fernando (2002): Espacios del imaginario latinoamericano. Propuestas de geopoética. La Habana: Editorial Arte y Literatura.

BARTHES, Roland (2009): "Semiología y urbanismo", en La aventura semiológica. Barcelona: Paidós.

CABRERA INFANTE, Guillermo (1992): Mea Cuba. Madrid: Alfaguara.

CABRERA INFANTE, Guillermo (1999): El libro de las ciudades. Madrid: Alfaguara.

CABRERA INFANTE, Guillermo (2007): La Habana para un infante difunto. Barcelona: Seix-Barral.

CABRERA INFANTE, Guillermo (2010): Cuerpos divinos. Barcelona: Galaxia Gutemberg.

CARPENTIER, Alejo (2004): La ciudad de las columnas. Madrid: Espasa Calpe.

ESTÉVEZ, Abilio (2004): Inventario secreto de La Habana. Barcelona: Tusquets.

HERNÁNDEZ, Luis Rafael (2009): "Lorca en Cuba, Cuba en Lorca". Revista de Occidente, núm. 337, pp. 69-83.

IZQUIERDO, Yolanda (2002): Acoso y ocaso de una ciudad. Río Piedras: Universidad de Puerto Rico.

LEZAMA LIMA, José (2009): Tratados de La Habana. La Habana: Letras Cubanas.

ROJAS, Rafael (2006): Tumbas sin sosiego. Revolución, disidencia y exilio del intelectual cubano. Barcelona: Anagrama.

ZAMBRANO, María (1968): "José Lezama Lima en La Habana". Índice, núm. 232, pp. 7-11.

ZAMBRANO, María (1996): La Cuba secreta y otros ensayos. Madrid: Endimyon. 